\title{
The digital revolution, data curation, and the new dynamics of food sovereignty construction
}

\section{Alistair Fraser}

To cite this article: Alistair Fraser (2020) The digital revolution, data curation, and the new dynamics of food sovereignty construction, The Journal of Peasant Studies, 47:1, 208-226, DOI: 10.1080/03066150.2019.1602522

To link to this article: https://doi.org/10.1080/03066150.2019.1602522

\section{Published online: 02 May 2019.}

Submit your article to this journal ¿

Џ Article views: 1493

Q View related articles ๘

View Crossmark data $₫$

4

Citing articles: 4 View citing articles $\llbracket$ 


\title{
The digital revolution, data curation, and the new dynamics of food sovereignty construction
}

\author{
Alistair Fraser \\ Department of Geography, Maynooth University, Maynooth, Ireland
}

\begin{abstract}
Technological change has given rise to the so-called 'digital revolution' (DR). How the DR affects food sovereignty (FS) construction remains unclear. This paper explores a balanced point of view, which highlights some key reasons why the DR is bad news for FS but also identifies features of the DR that could bolster FS construction. At the centre of the argument is the concept 'data curation,' which connects data-laden, algorithminfused capitalist enterprises to users of diverse technology services and devices. I examine how data curation is practized by capitalist enterprises in the food sector, focusing in particular on developments pursued by the British food retailer Ocado. I then examine three forms of data curation of relevance to FS construction. Emphasizing the urgency of attending to these new dynamics of FS construction, I conclude the paper with a call for further research on data curation practices of relevance to FS scholars and activists.
\end{abstract}

\section{KEYWORDS}

food sovereignty; digital revolution; data curation; food retail

\section{Introduction}

Numerous aspects of everyday life have been altered by the emergence and proliferation of digital services and devices connecting billions of digital subjects via the Internet. Characterized in a straightforward manner as a 'digital revolution' (DR) (Kitchin 2014b) 'digital' because the core technologies pivot on the transmission and storage of binary code; and 'revolution' because of the impact many digital technologies are having on society (boyd and Crawford 2012) - scholars in the area of critical food studies have examined its significance to food culture generally (Goodman, Johnston, and Cairns 2017), and there have been critical considerations of the impact of data-laden, algorithm-infused processes affecting agricultural production (Bronson and Knezevic 2016; Carolan 2017a, 2017b; Fraser 2018).

Under-explored hitherto, however, is the DR's impact on food sovereignty (FS) construction (e.g. see Wittman 2009; Wittman, Desmarais, and Wiebe 2010; McMichael 2014; Schiavoni 2017). Do proliferating digital technologies hinder or do they enable FS construction? In response, my aim in this paper is to critically analyse a wide range of materials about the $\mathrm{DR}$, specifically with a view to using them to prompt a conversation among FS scholars and activists about what practices need to be better understood and pursued more effectively. 
Key facets of the DR muddy the FS waters - with some developments and processes making FS a more distant reality and others prompting optimism that digital technologies might bolster FS construction. There should be a sense of urgency among FS advocates to grapple with, analyse, and refine practices used to engage with these developments.

As I explain in the next section of the paper, one key practice is 'data curation.' Drawing especially from scholars in the field of critical data studies, I conceptualize data curation as a pervasive and expanding component of digital life. I then use the remainder of this paper to argue that data curation is becoming an important component of the new dynamics of FS construction arising from the DR, which introduces new constraints upon, and possibilities for, FS construction. Regarding constraints, I examine data curation practices evident in the actions of some prominent capitalist enterprises in the food industry, especially the British food retailer Ocado. I focus on actions that complicate the task of FS construction in new, relatively uncharted ways. I then turn to consider data curation as an opportunity for FS construction. I specifically focus on the role data curation is currently playing in efforts to raise FS consciousness, strengthen FS coalitions, and expand the commons.

\section{Data curation}

A fruitful way of conceptualizing practices in the digital era, which is alluded to across the 'quickly evolving' (Burns, Dalton, and Thatcher 2017) area of critical data studies (e.g. see Dalton and Thatcher 2014; Dalton, Taylor, and Thatcher 2016; Iliadis and Russo 2016), is to imagine technology companies and the individuals who use digital technologies as involved in curating data (see specifically Van der Velden 2015, 8; Allen and Vollmer 2018, 25; Farhadi 2018, 141; Zook 2017, 5). I re-phrase this as 'data curation' by taking cues from insights about the spatio-temporal dynamics and dimensions of curation as a practice of selecting, representing, and preserving content (Joy and Sherry 2003). In this view, curation entails deciding what content to care for and making decisions about ways of representing or displaying it. It can involve creating an event; translating its significance; positioning it with respect to what has gone before or what might follow it; and calculating how the event can be delivered and made possible given material constraints and possibilities. But curation is also about anticipating and expressing a degree of willingness to engage contingencies. A curator in a museum or art gallery operates in full knowledge that unpredictable responses will occur; that the curated content will have some form of vitality but always in contingent, unknown ways. Curation is always tentative, experimental.

Per this everyday sense of the term curation, I conceptualize data curation as a practice that involves presenting, positioning, and translating data amidst an expanding constellation of contingencies. A graspable everyday example to consider here is when an individual writes a message on the social media platform Twitter. The tweet immediately becomes a data point and the text or links it contains will be positioned and translated by algorithms and other people. Its author has acted in a way that produces data that platform companies such as Facebook or Google control and monetize (Thatcher, O'Sullivan, and Mahmoudi 2016). But the Twitter user cannot predict what will happen next. A tweet critical of the Israeli government could be seized upon by pro-Israeli groups or their automated 'bots' and the author might begin receiving abusive messages. A tweet with a certain hashtag might be ignored or strike a chord; its impact could be miniscule or 
enormous (think: \#MeToo). As such, the hashtags that 'trend' on a social network such as Twitter cannot be predicted, nor can anyone determine what impact they might have.

This type of activity, multiplied across numerous platforms and billions of accounts, is data curation: acting in a way that draws upon and makes data, in one form or another, which is positioned and translated with respect to a wider array of contingencies. Amidst this general scene, therefore, digital subjects necessarily anticipate and engage contingencies when they manage digital services and devices. Data curation - whether it involves a company tweaking the look of an app or the purpose of a service; or an individual user deciding to click, swipe, or tap a device - occurs with an understanding that actions will produce effects that could take on a life of their own.

Data curation is pervasive. Engagement with digital technologies is germane in contemporary society ${ }^{1}$ (to the extent even that those who refuse them can be registered as a nonuser and therefore still caught up in the process). Digital technologies enrol participants in emerging chains of responses that create data (e.g. see boyd and Crawford 2012; Pickren 2018; Cheney-Lippold 2017). Participating in a 'planetary cognitive ecology' (Hayles 2017) constituted by digital technologies requires that digital subjects (companies, governments and individual users) respond to numerous invitations and prompts (to tweet, send an email, like a Facebook post, use a cloud storage service such as Dropbox, hail a ride on Uber, create a new app, monitor a messaging service, and so on). Throughout this process, data 'reserves' are formed that 'actualize algorithmic computation' (CheneyLippold 2017, 195) in ways that variously constrain and offer affordances, from one minute to the next. Action, practice, engagement in the digital era - opting to click on one option or swipe or another - unavoidably involves data curation: companies, governments, and individual users are presenting, positioning, and translating data in contingent ways on an ongoing and expanding basis when they engage society via digital media.

In turn, I argue data curation needs to be viewed as a significant practice emerging from the DR. It creates new effects. For example, consider the constant 'meeting up' in online space of capitalist enterprises and technology users who engage in an ongoing backand-forth as they tweak and curate arrangements of services and devices. For Villi (2012), this back-and-forth gives rise to a 'curation loop' (see also Pedersen and Burnett 2018) whereby capitalist enterprises and users are implicitly (and sometimes explicitly) curating data together in data-laden, algorithm-infused actions that identify popular and/or valuable digital content. On devices, for example, technology providers roll-out new updates or features that users can embrace or reject. These capitalist enterprises are curating data with a view to analysing responses and conceptualizing new ways to activate users and generate traffic through the online meeting points where ads or paid-for services are available. Analysing the emerging reserves of 'big data' - stores of data 'generated continuously, seeking to be exhaustive and fine-grained in scope, and flexible in its production' (Kitchin 2014a, 2) - presents companies with extensive opportunities to develop new, although far from perfect, insights about how to develop new products, access new markets, reduce costs, or create new sources of demand.

\footnotetext{
${ }^{1}$ Of note here is that, according to the United Nations Development Programme (UNDP) (2016), there were 98.5 mobile phone subscriptions per 100 people worldwide in 2015 and $43.7 \%$ of the global population was an internet user, although the figures for 'developing' and 'least developed' countries were, respectively, 92.9 per 100 people and $36.2 \%$, and 68.3 per 100 people and $12.6 \%$. In other words, digital technologies are pervasive but not universal. Even so, a growing proportion of the world's population is engaging with data.
} 
For their part, users curate their engagement with these services and devices - not only adjusting privacy settings or the layout of apps on a homescreen but also by deciding to use them at all - and data about how they are curating is sent back to technology companies, which then informs how code or algorithms will be written or set to work in the future (Pasquale 2015). When users spend time online, their data curation involves participating in the identification of opportunities - they generate, as it were, 'co-curated openings' - where new forms of content can be inserted or pulled into the overall process, thereby shaping how capitalist enterprises and users make calculations about future investments, decisions, and directions. A significant proportion of humanity is actively, although mostly implicitly, ${ }^{2}$ and without receiving wages, working online to establish what commodities work, sell, and have a future. Proliferating digital technologies places an onus on all capitalist enterprises producing goods and services discovering effective access points to the data curation loop if they are going to understand and retain a profitable position within markets increasingly shaped by digital technologies. Capitalists - in the tech sector and beyond - are seeking effective access points to the data curation loop. One reason the DR expands, therefore, is because the curation loop presents a way to connect capitalist enterprises and consumers with numerous types of content and products (ads, goods, services, platforms). Today, building competitive advantages stems from learning how to tweak arrangements of services (Paasonen 2016) and curating data effectively (Srnicek 2017).

The rapid-growth and valuable technology companies behind the DR use similar, although context-specific, processes of data curation. Google uses data curation regarding search activity to sell advertisements; Facebook matches ads with data it has curated regarding tastes, preferences, or profiles; Instagram, Pinterest, Snapchat all pursue their versions of data curation to find profitable ways of attracting advertisers to high-traffic spaces on apps or web sites. There is little to be said for encouraging users to generate data - an expensive commodity to store in data reserves (Cheney-Lippold 2017) - if effective curation does not follow. The challenge facing all capitalist enterprises amidst the DR is to intervene and respond to emerging results from the curation loop, with a view to constructing an ongoing arrangement of materials that can be profitably exploited. The challenge facing all individuals amidst the DR is to navigate the constraints and affordances emerging from the services and devices inviting their response, conceivably in ways that construct new and more equitable arrangements of materials. Objectives might differ and the data they can tweak can vary quantitatively, but data curation is nevertheless the practice pursued today by capitalist enterprises and users to meet these challenges.

\section{Data curation in the food industry}

As the following discussion demonstrates, there is mounting evidence that data curation is becoming a fundamental part of economic strategy in the food economy. Prominent players are pursuing data curation as part of an ongoing interplay between their practices, the practices of other capitalist enterprises and regulators, and consumers. At issue are multiple overlapping engagements whereby businesses in the food sector are trying to

\footnotetext{
${ }^{2}$ So sometimes explicitly, for example when users provide direct feedback about the functioning of services.
} 
alter arrangements in ways that suit them, regardless of whether the overall objective is to gain market share or generate new sources of profit further down the line. I now review some headline developments and then identify why there is cause for concern for FS advocates.

Consider first the dramatic growth of the technology firm Amazon, its recent move to deliver groceries in addition to consumer goods, and then its USD 13.4 billion purchase of the Whole Foods supermarket chain (Wingfield and de la Merced 2017). Amazon is an incredibly aggressive player in the technology and consumer retail sector (Manjoo 2017). Infamously, beyond its size and concomitant economies of scale, a key source of Amazon's competitive advantage is its determination to map and model the market, using extensive and intensive data analytics to understand competitors, target their customers, and identity opportunities where it can endure short-term losses with a view to wiping them out. As it operates in markets for commodities such as books or consumer electronics, so it operates in food retail (with strong indications that it is gaining market share at the expense of unionized competitors [Corkery 2018]). There is every reason to expect that Amazon's move into food will disrupt, dismantle, and re-develop markets according to its logics; that its pivot to food will have stark effects on producers near and far, on the calculations of supplier firms, on the expectations of consumers, and on socio-political cultures of food as a whole (e.g. see Wingfield, Mozur, and Corkery 2018). Few developments associated with the DR have presented such bad news for those advocating FS as Amazon's realization that serious money can be made in high volume food retail.

Although Amazon is notoriously secretive about its operations, some sense of what it might pursue can be gleaned from evidence about a British company operating in the grocery sector: Ocado (Baldwin 2016; Herrod 2016; Tugby 2017). As part of its growth strategy, Ocado has reached out to industry publications to visit and conduct interviews about its new warehouse technologies. As I now demonstrate, secondary materials on Ocado's emerging practices shed significant light on the sort of developments that competitors such as Amazon, but no doubt many other companies in the food industry, are pursuing. Per my conceptualization, data curation is a core concern in understanding what Ocado is trying to achieve.

Unlike its competitors - Tesco, Morrison's, or Asda - Ocado only operates online: customers use its website or smartphone app to select groceries, which Ocado delivers to their home. At this level alone, Ocado is emblematic of what is becoming possible in the new data-laden, algorithm-infused food economy: new players with non-traditional business models gaining a foothold in a competitive sector, much like disruptive entrants in other sectors, perhaps most notably Uber or Lyft (e.g. Zipkin 2017). But Ocado also attracts attention because of its heavy investment in robotics, artificial intelligence, and machine-learning, which the firm has directed toward creating a highly-automated, algorithm-intensive packing warehouse. Its patented Ocado Smart Platform (OSP) guides a hive-like warehouse, with robots 'buzzing around [at] four metres per second [and] "spoken to" 10 times every second by Ocado's patented communication system' (Tugby 2017). OSP 'choreographs the most efficient route for the robots to take, ensures they don't collide with each other and optimises storage within the hive, working out the best spots to replace totes based on upcoming orders' (Tugby 2017). OSP is, therefore, a fledgling demonstration of the power of machine learning, operating in a neural 
network, to decide the 'location of products, and the stations at which pickers work' (Herrod 2016).

It is tempting to look beyond the role of humans in this sort of action: the work performed within Ocado's warehouse and distribution network is about robots, automation, algorithms, and the curation of big data on customers, their preferences and tastes, and locations. But the firm's activities definitely speak to the emerging significance of data curation performed by humans. As Matt Sloane (quoted in Baldwin 2016; my emphasis), one of Ocado's chief technologists has pointed out:

There's a whole load of robotics there, pick smarter, quicker, it's really clever technology. Big data is very exciting [...] But to make it work, you've got to make sure all of your systems are exposing data of any interest. All sorts of wonderful things are possible, you have to put the work in to expose the data. I never stop putting effort to make sure that is happening. Because there are enormous dividends down the line.

Similarly, regarding the location of products within the warehouse, Herrod (2016; my emphasis) notes that:

... a simple algorithm was tested with the fastest moving goods located close to the pickers, but it became apparent that other factors needed to be brought in too. Rather than working out the best parameters, the engineers trained neural networks to calculate the critical factors for where products are placed. Some are obvious, such as not putting heavy products high up, and whether items can be picked up with one hand or require both.

In short, it is the people working within Ocado - the engineers, software developers, chief technologists - who 'put the work in' and 'train' the system. Ocado is data-laden and algorithm-infused and this means it must curate those data effectively and according to its objectives, as one of its chief technologists James Donkin (quoted in Herrod 2016, my emphasis) makes clear in the following quote:

One of the good things about Ocado is that we have lots of data. We have data coming out of everything; sensors, pick stations, robots and so on, and as an experimental project they trained the neural net over a few months, and compared it with other attempts, and it worked. It got the productivity improvement that we were looking for ...

Such 'productivity improvements' might only concern split-seconds or fractions of one pence, but they add up to more deliveries per van per week - 166 per week in FY16 compared with 151 in FY12 (Ocado 2015) - and boost the firm's gross margins.

This is, therefore, in-house, proprietary data curation using machines, algorithms, and humans to develop effective management systems that can provide oversight, deliver on-time maintenance, and control strategy according to corporate objectives. But it is also necessary to view Ocado's activities emerging from meeting-up online with customers and others. Ocado's 'reserve' of data (Cheney-Lippold 2017) focuses on the movements of robots inside its warehouse in relation to an ongoing back-and-forth with its customers. A core issue for Ocado is precisely whether it can curate what happens inside the warehouse with the world outside; that is, with the markets in which Ocado wants to succeed, with customers who expect to see their orders fulfilled correctly; and with actions taking place elsewhere, such as on the website, on road networks along which delivery vans will move, or the hundreds of thousands of homes where customers might begin making an order (and possibly managed autonomously). The ongoing tweaks 
and improvements set in motion by Ocado's data curators and possibly managed autonomously respond to the contingent world beyond the warehouse in an iterative back-andforth - a curation loop - which enrols consumers and others (road users, transportation networks, competitors) to co-curate new openings; that is, new insights about how it can develop profitable procedures within the market in which it is active.

Action elsewhere in the food system is increasingly based on similar dynamics. For example, data curation is a key element in the emergence of new players and business models, including the (to-date, secretive) agreement between Nestlé, the world's largest food processing corporation and Samsung, the world's largest electronics manufacturer. Signed in 2016, the deal entails a research collaboration which will assess the potential to improve nutrition science using digital sensor technologies (Nestlé 2016). For Nestlé, the deal comes on top of numerous other attempts to take advantage of new data streams. In its Malaysian headquarters, for example, 'there is a room with a screen covering an entire wall that tracks key words related to the company's products on the Internet [...] The sales force studio is where Nestlé's Malaysian digital acceleration team, which was set up in early 2014, analyses consumer trends specifically for the company's social media campaigns and market research' (The Nation 2016). Regarding demand planning, moreover, Nestlé has used 'predictive analytics' supplied by SAS ${ }^{3}$ to 'improve forecasting accuracy while minimizing overstocks' (Blanchard 2016), a complex undertaking for a firm producing, stocking, and moving around 10,000 items. With respect to its deal with Samsung, then, Nestlé is reiterating its determination to make the most of data, not only to analyse and anticipate, as it is already doing, but also to innovate and develop new strategies. It sees scope to begin taking advantage of the 'data from sensors and devices in our daily lives, such as mobile phones, wearables and "smart" homes [to] provide individuals and families with personalised recommendations around nutrition, lifestyle and fitness through a single digital health platform' (Nestlé 2016).

Nestlé's competitors are also pursuing data-laden partnerships and alliances. In 2017, for instance, PepsiCo signed a strategic agreement with the Chinese internet firm Alibaba to 'carry out more innovative experiments' that will take advantage of the latter's 'big data capabilities and omnichannel solutions' (PR Newswire 2017). Mondelez, moreover, have used Alibaba's platform to create a new marketing campaign, which responded to 'a waning appetite for its signature crème-filled sandwich cookie Oreo in one of its most important markets, China' (Kit 2016). As Mondelez's Ganesh Kashyap noted:

'From our data, we found out that millennials between the age of 18-30 were familiar with Oreo, but they didn't have a connection with the brand when they make purchases online.' [In response] Mondelez rolled out a campaign last year, which allowed customers to select the artwork and customise personal messages on their Oreo purchases. Despite having to pay triple the price, the campaign was a big hit among Chinese millennials. 'Not only did it drive brand engagement levels with millennials for the franchise, it grew the sales of Oreo in the country,' said Mr Kashyap. 'For a millennial consumer, if you want them to buy online, it must be a good deal but at the same time, they are also willing to pay three times the price for an experience to customise their Oreo box. I think that's the dichotomy that exists in the minds of the millennials and data allowed us to uncover and solve it, he added. (Kit 2016; my emphasis)

\footnotetext{
${ }^{3}$ SAS emerged from the agricultural sector in the US to become a leading provider of statistical software used in numerous industries today.
} 
To reiterate, this sort of action is about using data to reveal new insights. But the performative and iterative element about this type of work - the sense that insights can equate to new products on the market once evidence emerges that consumers have been sufficiently activated - requires viewing it as an issue of data curation. For corporations such as Pepsi or Nestlé, investments are directed at exploiting the opportunities that emerge from implicitly and explicitly working with users/consumers to produce cocurated openings. Given the significant extent to which innovation by businesses in the food industry revolves around ongoing line extensions - where existing successful products are tweaked with a new flavour or style of packaging (e.g. see Patel 2007; Moss 2013) - it is by exploiting these co-curated openings that 'actionable insights' can be revealed, such as product tweaks or marketing prompts that draw in new customers (see Roberts 2016).

\section{Cause for concern}

I now highlight three reasons FS advocates should be concerned by the developments charted in the preceding section. First, Ocado's practices alert us to the level of automation taking shape in critical spaces within the food system. But automation here is not only about the movement or packing of commodities. Although Ocado still requires human data curators, its system relies heavily on automated decision-making via algorithms and machine learning. Elsewhere in the food system, key decisions about plant diseases, seed genetics, or customer preferences also indicate a pervasive and expanding pursuit and practice of data curation that employs opaque (inevitably biased), proprietary algorithms and massive computational assemblages to calculate how food can be produced, moved, and sold. ${ }^{4}$ The emergence of 'technical cognition' (Hayles 2017) in the food system results in increasing quantities of information interpreted and given meaning by automated services and devices. When algorithms make decisions, for example in HighFrequency Trading systems, they 'are constantly interacting with other algorithms, generating a complex ecology' (163), with algorithms hunting and confronting each other without human interference. 'Once created, they do not require any human agency to act. Indeed, humans are deliberately cut out of the circuit ...' (171). It follows that many of the most crucial decisions and investments shaping the planetary food system are beginning to involve opaque automated data curation practices that make democratic scrutiny of corporate action a fainter possibility. Ethical responsibility in the type of food system promoted by companies such as Ocado or Amazon lies with their software engineers, lawyers, executives. There are few reasons for FS advocates to have much faith in the virtue of any ethical stance they will take.

Second, data curation is becoming part of contemporary strategies to increase the market power of food businesses. Presenting, positioning, and translating data amidst wider contingencies is occurring with a view to improve how companies such as Amazon, Ocado, Nestlé, Pepsi, or Mondelez can understand, engage, and control markets for food. Developments behind-the-scenes in Amazon's corporate headquarters, more publicly in Ocado warehouses, or in Samsung, Nestlé, Pepsi, or Mondelez research laboratories aim to exploit digital technologies to secure future profits. The results of

${ }^{4}$ For other examples of robots in agriculture, see: http://robohub.org/topic/Environment-Agriculture/ 
their experiments and projects will be seen in alterations of the internal layouts of supermarkets, in the flavours or styles of food we might find on our dinner tables, the customer's experience of buying food, ${ }^{5}$ and conceivably in the food industry's expanded power to shape what happens on farms worldwide. Data curation is occurring with a view to creating plans and projects that will inevitably run counter to the FS vision of an equitable and just food system. In this sense, the alternative arrangements called for by FS advocates clash with the new logics driving the food system. Amidst pervasive and proliferating digital technologies, an open question is whether alternative arrangements stand any chance of surviving given the uneven distribution of data processing power and data curating capabilities, with leading-edge capitalist enterprises advancing a view of the entire planetary food system simply as a series of data points, with 'data coming out of everything' and engineers in position to tweak code in ways that secure future profits.

Finally, the materials above draw attention to emerging relationships between data curating capitalist enterprises and the individual who needs to eat. The core issue for Ocado is using data curation to construct an ongoing arrangement of materials (data, goods, staff, machines, delivery vehicles) that the firm can profitably exploit. Its prospects hinge on whether it can effectively curate data and exploit insights garnered from the curation loop in which its customers are enrolled. But Ocado's owners also see their activities as part of an effort to demonstrate its value-creating possibilities and therefore sell the patented OSP in export markets. By curating data, Ocado is developing a suite of technologies the firm can sell to supermarkets globally, with unpredictable consequences for competitors and suppliers. As I have noted, critical decisions and processes affecting the food system are now coming under the influence of opaque Ocado-like proprietary systems designed and controlled by profitable enterprises relying on machine learning, neural networks, and their ability to put data to work to deliver 'productivity improvements'. But none of these systems will function or remain profitable without their owners continuing to accumulate data reserves, via processes of 'data colonialism' (Thatcher, O'Sullivan, and Mahmoudi 2016) that dispossess users of, and proceed to privatize, data about their everyday life decisions. The emergence of data curation in the food industry means customers will need to continue participating by handing over control of data about their food consumption practices. Ocado signals the possible emergence of a food system in which eating will be contingent upon the food consumer producing data.

\section{Data curation for food sovereignty construction}

I conceptualize FS construction as a process involving individual and collective action by food producers and consumers to develop new relations that value justice, solidarity, autonomy, and democratic control over the local and planetary food system; a process involving discrete but connected actors looking to establish mechanisms that can rearrange extant materials in ways that strengthen the position of small-scale food producers and protect the rights of billions of food consumers to eat healthy sustainably-produced food (see especially Wittman, Desmarais, and Wiebe 2010). The case for FS

\footnotetext{
${ }^{5}$ Including the price they might eventually pay, which could vary from one user to the next, much as the price of hotel rooms can be affected by the type of computer with which a search is conducted (Cheney-Lippold 2017, 187).
} 
hinges on the notion that a food system can exist in which the constituent components are re-arranged to engender justice. Where there is FS - or, at least, more FS than there was before - a wide range of ostensibly separate or broader conditions come together in such a way that injustices in the food system are reduced (and/or eliminated). Making FS possible therefore requires critical subjects pursuing multiple ongoing societal interventions, many of them quite localized in scope but often involving connections with allies in other places. FS construction can involve the design and roll-out of well-funded, -supported, and -intentioned projects and programs that can become particularly effective when they are matched by grassroots efforts to prompt and pressurize politicians to create appropriate public policy and continual promotion and defence of the virtues of FS amidst dominant neoliberal discourses that view market relations as a sufficient mediator of action in the food system (Edelman 2014). It also fundamentally entails struggles on the part of food producers in 'majority' and 'minority' worlds to contest and deconstruct elements of the corporate food regime (McMichael 2009, 2012), while creating alternative arrangements that engender sovereignty. Ultimately, FS construction hinges on the development and sustainability of new practices, as well as coalitions and alliances that support FS actions by securing new arrangements of laws and monitoring the political sphere. It is a complex task with many nuances and specificities, as revealed and explored by a large body of academic work, not least in this journal (e.g. see Patel 2009; Wittman 2009; McMichael 2014).

This part of the paper considers how data curation is becoming a new element within the extant complexities of FS construction. There are parallels with the practices of companies such as Ocado that use data curation, tied into the curation loop, to construct an ongoing arrangement of materials that can be profitably exploited. Of course, profitably exploiting arrangements of materials is not the objective of FS construction; but I argue that constructing FS still involves curating data with a view to constructing new and more equitable arrangements of materials. I highlight three issues.

\section{Data curation for FS consciousness}

Given the 'contested terrain' (Schiavoni 2017) on which FS construction occurs, approaches are needed that view it as 'dynamic, ongoing and open ended' (3); that is, as a process that interacts with a diverse range of 'struggles and initiatives [that provide] the very fabric' for making FS. A core consideration in FS construction is creating something akin to an ideal-type of 'small-scale, agroecological, peasant production' (Robbins 2015, 457); but another is finding ways to address the 'practical, immediate issues in the industrial food system' (451), especially its problematic dynamics, such as 'trade liberalisation, corporate concentration [and] long-term social implications, such as displacement and dispossession, dietary changes and a widening gap between producers and consumers; and a large impact on the environment in terms of biodiversity loss, soil depletion, deforestation and greenhouse gas emissions' (449). Creating and disseminating information about the food system as a whole, or indeed about its constituent parts, can help to shed new light on the problematic dynamics, long-term social implications, and struggles and initiatives interacting with FS construction. In other words, FS construction has a FS consciousness-raising component which can originate from efforts on behalf of FS movements but also from other sources. 
For example, as noted in recent scholarship on 'data activism' (Milan 2016; Gutierrez and Milan 2017), InfoAmazonia has emerged as a collaboration between journalists, data scientists, and indigenous communities and land rights activists to respond to displacement and dispossession in the Amazon region. They do this by working to 'obtain data from whistle-blowers, resort to opened public data, facilitate and gather crowdsourced data, appropriate data, and finally "datafy" primary research or generate their own data via sensors and other data-capturing devises [sic]' (Gutierrez and Milan 2017, 9). ${ }^{6}$ Although InfoAmazonia is not operating with respect to a FS framework, the type of information disseminated and the strategy for doing so is conversant with, and relevant, to the process of FS construction in a digital, data-driven world. Also of note here are actions on the part of the German non-profit, foodwatch. Foodwatch carefully curates its website, makes interventions on social media platforms such as Facebook and Twitter, and sends out regular e-newsletters to subscribers (Schneider et al. 2019). The objective is to develop knowledge that can inform action regarding the food economy. Its data-laden activities help to construct 'a digital space of invited participation' (3) in which the organization can communicate its 'proximity to consumers' (13) and 'create an affective atmosphere that mobilises issue-publics to assemble and act' (15). It is, then, an example of 'internet-based activism whose mobilising power lies in the ability to produce large aggregations of de-personalised engagement' (16).

What these actions point toward is the emerging power of critical subjects trying to make the most of algorithmic affordances: it is about curating data to send the right message to the right issue-public in the right manner, with the right tone and without making mistakes. It is an experimental calculation, mirrored today by numerous other groups and political campaigns - many of them with clearer connections to FS construction, such as FoodFirst, GRAIN, or the ETC Group - trying to engage distanciated others in dispersed overlapping social networks. There are limitations to this sort of action: when activism stays online, a risk is that citizens or activists rely too heavily on a passive form of resistance. But their significance remains: counter-publics like those developed by InfoAmazonia, foodwatch, FoodFirst, GRAIN, or the ETC Group undermine dominant narratives about the food system. If $\mathrm{FS}$ is a critique as much as it is a vision of an alternative food system, it follows that subaltern online activities such as these are (going to be) needed.

It is, moreover, helpful to dwell on the extent to which overt and behind-the-scenes practices of data curation are part of the scene here. Messages are carefully presented; work has to be performed to get news stories onto news feeds; tags on blog posts must connect content to metadata structures; and adjustments are needed on an ongoing basis to make web sites and social media campaigns relevant. The successes or failures of their actions hinge in part on how (data) activists curate data; on whether they can ensure their materials can be found; that they can navigate algorithmic shifts and changes and develop new ways of disseminating information. Developing an extensive online presence - as La Via Campesina has tried to achieve via use of videos, social media, blog posts, newsletters, and more - stems from the actions of astute technical actors who can develop and adjust data-laden strategies as changes occur in the internet

${ }^{6}$ The NGO Mapping for Change (http://mappingforchange.org.uk/) pursues similar practices (see Couldry and Powell 2014, 4). 
itself or in society more broadly. Raising FS consciousness, making the case for social change, increasingly looks set to involve data curation to monitor and disseminate news, connect with publics, and provide justification for arguments that new arrangements of laws or policy are needed. FS consciousness needs knowledge and information about the food system's faults. Actions like those pursued by groups such as InfoAmazonia or foodwatch are necessary, especially amidst emerging practices within the food industry that look to shield decisions from democratic scrutiny.

\section{Data curation to build coalitions and exert political pressure}

Data curation has a role to play in efforts to establish and maintain coalitions for FS construction. It goes without saying that FS construction relies on advocates and supporters physically meeting, whether to protest outside a World Trade Organization meeting or plan a schedule of events aimed at challenging a local or national law or policy development. Meeting 'virtually' also matters: organizers use new telecommunications technologies such as Skype; members of a peasant association use Whatsapp; linking and connecting involves Facebook; and so on. Thus, as literature on electronic activism in social movements has demonstrated quite clearly (Juris 2005; Milan 2015), contemporary technologies can be used in ways that bolster political mobilizations, with potentially dramatic (although not unidirectional) effects, as came to light in the Tunisian, Egyptian, and Syrian uprisings. Part of the scene here is the centrality of 'hyper-coordination' (Ling and Yttri 2002) via mobile phone and email, which is already a familiar feature of life, as anyone involved in FS construction will recognize. Astute use of everyday contemporary technologies can help to establish and connect counter-publics.

But beyond the everydayness of all this, the 'strategic calculation' (Licoppe 2004, 153) to establish and maintain a 'connected presence' (153) in movements building FS construction also calls attention to some striking specificities that involve data curation in new and potentially critical ways. The DR is altering the windows of opportunity that transnational agrarian movements might try to exploit. By mobilizing the 'crowd' to direct messages at government officials or petition parliaments, for example, FS advocates can apply political pressure and conceivably help to deliver crucial victories. Per the example of foodwatch, at issue is astutely curating data on supporters and opponents. Success hinges on knowing what messages should be directed where; using analysis of prior campaigns to learn from earlier mistakes or victories; and carefully piecing together sequences of online actions that make the most of what the DR affords and permits. Making effective use of social media requires deciding what to put onto display, calculating what tweets or posts to release, and labouring to create the openings within which new, potentially substantive connections and actions might occur. ${ }^{7}$

In some keynote policy successes for FS advocates, therefore, there is evidence that practices akin to data curation have been playing a small part. In 2013, for instance, social movement campaigners in Venezuela 'came together from across the urban-rural divide under the banner of "Venezuela Libre De Transgénicos" ("GMO-free Venezuela")' to protest a national seed law that would have legalized GMOs (Schiavoni 2017, 21).

\footnotetext{
${ }^{7}$ Consider also how effective use of social media is a serious consideration in conferences or events, with Twitter hashtags and post-conference 'multimedia stories' used (as a way to satisfy funders but also) to connect wider audiences.
} 
The campaign 'significantly influenced state action' (21) by stalling the proposed law and calling for a new proposal, which was passed in December 2015 and which bans 'both domestic production and importation of transgenic seeds' (21). One component of this process involved rudimentary social media tactics - tweets, hashtags, trending topics akin to those seen in numerous other recent political movements in Tunisia and Egypt (Bruns, Highfield, and Burgess 2013). Twitter's advanced search facility demonstrates that in 2013 alone the exact phrase 'Venezuela Libre De Transgénicos' was mentioned in 347 tweets by individuals and groups, such as the Campaña Nacional por una Venezuela Libre de Transgénicos (OGM), Agrotóxicos y Agronegocio (the National Campaign for a Venezuela free of GMOs, agri-chemicals and agribusiness) (Twitter 2017) (since 2013, the phrase has been mentioned on average 45 times per year). These actions, which require that FS advocates curate services and devices to then target messages and build momentum around issues on social media, point toward the emerging importance of data curation practices. They also alert us to the scenario that future FS successes in the political sphere might involve data curation, with social movements and their allies and supporters using social media or other digital technologies to apply sufficient pressure as part of efforts to re-arrange the materials affecting the lives of food producers or consumers. FS construction is not only an issue of building coalitions and alliances to apply political pressure; but on those occasions when expressions of political pressure can make a difference, data curation is becoming part of the scene.

\section{Data curation for protection of the commons}

As I have noted, developments in the food industry indicate there is a drive to colonize and privatize everyday life (Thatcher, O'Sullivan, and Mahmoudi 2016), even to the extent that eating could become bound up with producing data. To counter these efforts, data curation can be used to protect and expand the commons, as I now discuss via use of two examples.

First, consider the case of Farm Hack (Carolan 2017a), which involves moves on the part of thousands of farmers to counter dependence on 'software technicians and implement dealerships' (8), and which arises because much of today's farm machinery relies on software and sensors that agricultural technology providers (ATPs) shield from farmers (see also Carolan 2017b; Fraser 2018). Although Farm Hack specialists might not be linked explicitly and ideologically with FS construction, I argue the group's efforts to become a 'living repository of knowledge' (Carolan 2017a, 823) and pass on tacit knowledge to future generations speaks to a central component in constructing FS: specifically, sovereignty to understand, tinker with, repair, and use components essential to food production despite a legal architecture which seeks to protect the copyright of farm machinery manufacturers. This is about expanding the commons amidst efforts by ATPs and other corporate actors to privatize everything (see Kloppenburg 2014).

Propagating Farm Hack's knowledge will also take place offline in face-to-face communications, for example. But when expanding the commons does entail online activity, data curation is an important consideration. On the web site http://farmhack.org/ for instance, the community passes on a variety of 'hacks,' connects allies in conversations, provides links to supportive organizations, and runs a blog which ties content into social media platforms such as Facebook and Twitter. Farm Hack's online activities 
occur via an iterative back-and-forth to co-curate content and knowledge, with the algorithms of social media companies enrolled in the process, for example when Facebook's news feed deems a new Farm Hack blog post worthy of inclusion in a user's timeline. Labour is needed to maintain and adjust this 'space,' especially in the context of companies such as Facebook adjusting their algorithms, which then places an onus on technical workers in groups such as Farm Hack spending time to re-configure tags or metadata. Input is required from those in the community to maintain this new region of the commons and undo the almost-inexorable drift of data into the reserves controlled by ATPs and other technology companies.

Much the same applies to a second example here, specifically efforts to disseminate knowledge regarding agroecology. The commons regarding agroecology is constructed via practices akin to 'crowdsourcing,' as demonstrated by the careful, extensive, and progressive forms of 'horizontal communication' charted in the campesino-to-campesino (CAC) movement in Cuba (Rosset et al. 2011). Using the 'crowd' - peasant producers who promote agroecological farming - to source insights and cull resources to build agroecology is increasingly at issue in 'cluttered' rural spaces 'awash with NGOs, reformist and reactionary farmers organizations, foreign foundations, and government and inter-governmental programs all touting a sometimes intentionally confusing mixture of a pre-packaged Green Revolution, sustainable agriculture, organic farming, etc.' (187-188; also see Borras 2010). Workshops, field visits, and books constitute one way for agroecological knowledge to be held in common and disseminated. However, the proliferation of digital technologies today suggests younger food producers and future generations will also require digital repositories of agroecological knowledge. Using services such as YouTube to promote agroecology - as FS-friendly organizations like the Transnational Institute have tried - might not be too problematic in the shortterm. Over the longer-term, however, protecting and expanding the commons for FS construction should use cooperative digital architectures where subaltern knowledge can be held in common and shared without generating advertising revenue for corporations such as Alphabet, Dropbox, or other start-ups. At issue should be 'data sovereignty' (Fraser 2018) whereby an agroecological commons constructed via 'crowdsourcing' can exist outside of the curation loop and without contributing to the data reserves controlled by corporations such as Facebook. Effective data curation by technicians with advanced skills is needed; resources, talent, and determination are required to present, position, and translate digital content and data regarding agroecology. Amidst 'data colonialism' (Thatcher, O'Sullivan, and Mahmoudi 2016), data curation can protect and expand the commons and, in the process, encourage and conceivably facilitate FS construction.

\section{Conclusion}

As the digital revolution gathers pace, those involved in FS construction, and those who support the process, are confronted with new dynamics. On the one hand, there are developments that suggest the chances of constructing FS are slipping away. In agriculture, food processing, and food retail, capitalist enterprises are curating data with a view to creating new arrangements of materials that can be profitably exploited, with significant help from opaque, proprietary algorithms designed and managed by human teams with 
visions of a future food system that few (if any) FS advocates will support. New services and products are appearing that compute food in terms of 1's and 0's, thereby occluding alternative understandings, for example regarding the socio-cultural or historical meaning of food or land-based life. On the other hand, and as I have demonstrated in the preceding section, FS advocates can use digital technologies in exciting ways; there are latent possibilities and affordances to exploit. Making the most of these technologies via data curation can help stitch together diverse interests and the visions of campesinos in a place such as Cuba, small-scale producers in a place such as Spain, and food consumers all over the world. ${ }^{8}$ Data curation is becoming a component in contemporary efforts to arrange materials in ways that bolster subaltern visions of the food system.

The considerable extent to which the DR alters the dynamics of FS construction poses two urgent and important challenges for FS advocates to address. The first concerns the actions of transnational corporations using data curation in the food sector. Precisely because the DR is occurring in ways that bring capitalist enterprises and users together in new chains of social relations, FS advocates must continually attend to emerging data curation practices in the food sector (and beyond). The DR is productive of an inter-hesitant future as a wide array of capitalist enterprises tries to figure out how they can become or remain profitable amidst a new (increasingly digital) economy that promotes (although unevenly, in geographical terms) the formation of an atomized, sedentary population to be serviced by enormous transnational corporations. New and as-yet unanticipated features will emerge, many of which will, per the example of Amazon moving into food retail, present new obstacles in the way of FS construction. The radical vision of FS risks becoming a minor blot on an otherwise digitized landscape dominated by capitalist enterprises whose shareholders will inevitably look to eliminate the chances of justice, solidarity, autonomy, and democratic control over the local and planetary food system. As a consequence, sustained activism and research is needed to examine and understand practices of data curation by corporations such as Monsanto (e.g. see Plume 2016) or Nestlé, as well as the new players (Amazon, Samsung, and others). For their part, astute FS activists might explore new ways of using data curation to shed light upon and oppose this emerging scene. For researchers, meanwhile, the task, in part, should be to overcome significant methodological challenges. In the context of intense competition for intellectual property and fears regarding corporate espionage, the DR complicates data collection. It is, for example, unusual to find secondary materials like those I have used regarding Ocado. Moreover, the type of ethnographic research that scholars might like to pursue amidst developments such as expanding corporate biofuel projects (e.g. see Gingembre 2015; Millar 2016) is difficult when the object of study is (often, spatially dispersed) data scientists or software engineers in research laboratories where new intellectual property is emerging (Kitchin 2017; also see Rosenberg 2007; Neff et al. 2017). Novel methodologies, such as web scraping (e.g. see Brown 2017) or following debates on online forums (Kitchin 2017, 24), need to be explored (see also Milan 2016).

\footnotetext{
${ }^{8}$ Crucially, moreover, even in contexts where the impact of smartphones and the Internet is marginal - perhaps because data plans or devices remain too expensive; or because (mobile) broadband coverage is weak - there is every reason for critical analyses of FS construction to remain alert to data curation.
} 
The second challenge is to identify, understand, and promote how data curation for FS construction can be made more effective. Whether the issue at hand is raising consciousness, strengthening coalitions to apply political pressure, or protecting the commons, data curation does not only require labour, hard work, talent, and determination but also a concerted ongoing effort to learn what works. The dynamics of FS construction today place newfound emphasis on critical digital subjects knowing what data should be presented, calculating how data can be translated effectively, and managing to mobilize data in ways that navigate contingencies and conceivably manipulate the possibilities or affordances of the DR. An emerging danger for FS advocates is that neither the DR nor data curation are awarded the significance they deserve by non-technical leadership. Learning what works - and learning from earlier mistakes - cannot be the sole preserve of technical workers in FS coalitions. As such, significant scope exists for auto-ethnographic research on data curation for FS led, for example, by the technical teams operating behind-the-scenes in organizations such as La Via Campesina or GRAIN (or written by scholars researching in collaboration with them); but also by non-technical FS advocates who have nevertheless accumulated knowledge of data curation. Unlike the situation facing researchers of data curation in the corporate world, research with technical teams in organizations working to achieve FS could reveal pertinent insights about how the affordances of digital life, and the array of contingencies engaged by data curation, are exploited to create novel and potentially 'productive' forms of resistance (e.g. see Ettlinger 2018). FS scholars and activists can acquire new insights if they remain alert to data curation.

\section{Acknowledgements}

The author would like to thank Nancy Ettlinger and the anonymous reviewers for helpful comments and suggestions on earlier drafts. Any errors and omissions are my own.

\section{Disclosure statement}

No potential conflict of interest was reported by the author.

\section{Notes on contributor}

Alistair Fraser is a lecturer in the Department of Geography at Maynooth University, Ireland. He holds a PhD in Geography from the Ohio State University, USA. His first book is Global Foodscapes: Oppression and Resistance in the Life of Food (Routledge, 2017). Other works include articles in Journal of Peasant Studies, Journal of Rural Studies, Environment \& Planning A, and Geoforum. Email: Alistair.Fraser@mu.ie

\section{References}

Allen, W. L., and B. A. Vollmer. 2018. "Clean Skins: Making the e-Border Security Assemblage." Environment and Planning D: Society and Space 36 (1): 23-39.

Baldwin, C. 2016. "Interview: Ocado on Open Source, Data and Warehouse Automation." Essential Retail, August 5, 2016. http://www.essentialretail.com/big-interviews/article/57a302b8d9fb4interview-ocado-on-open-source-data-and-warehouse-automation.

Blanchard, D. 2016. "How to Build a Smarter Supply Chain." Material Handling \& Logistics, June 29. 
Borras, S. M. 2010. "The Politics of Transnational Agrarian Movements." Development and Change 41 (5): 771-803.

boyd, D., and K. Crawford. 2012. "Critical Questions for big Data: Provocations for a Cultural, Technological, and Scholarly Phenomenon." Information, Communication \& Society 15 (5): 662679. doi:10.1080/1369118X.2012.678878.

Bronson, K., and I. Knezevic. 2016. "Big Data in Food and Agriculture." Big Data \& Society 3 (1): 2053951716648174. doi:10.1177/2053951716648174.

Brown, S. 2017. "Web-scraping for Social Research: A Tutorial." Eye on the World, November 27. https://maynoothgeography.wordpress.com/2017/11/27/web-scraping-for-social-research-atutorial/.

Bruns, A., T. Highfield, and J. Burgess. 2013. "The Arab Spring and Social Media Audiences: English and Arabic Twitter Users and Their Networks." American Behavioral Scientist 57 (7): 871-898. doi:10.1177/0002764213479374.

Burns, R., C. M. Dalton, and J. E. Thatcher. 2017. "Critical Data, Critical Technology in Theory and Practice." The Professional Geographer 70 (1): 126-128. doi:10.1080/00330124.2017.1325749.

Carolan, M. 2017a. "Agro-Digital Governance and Life Itself: Food Politics at the Intersection of Code and Affect." Sociologia Ruralis 57 (S1): 816-835.

Carolan, M. 2017b. "Publicising Food: Big Data, Precision Agriculture, and Co-Experimental Techniques of Addition." Sociologia Ruralis 57 (2): 135-154. doi:10.1111/soru.12120.

Cheney-Lippold, J. 2017. We are Data: Algorithms and the Making of our Digital Selves. New York: New York University Press.

Corkery, M. 2018. "Grocery Wars Turn Small Chains Into Battlefield Casualties." New York Times, March 26. https://www.nytimes.com/2018/03/26/business/grocery-wars-small-chains.html.

Couldry, N., and A. Powell. 2014. "Big Data From the Bottom up." Big Data \& Society 1 (2): 2053951714539277. doi:10.1177/2053951714539277.

Dalton, C. M., L. Taylor, and J. Thatcher. 2016. "Critical Data Studies: A Dialog on Data and Space." Big Data \& Society 3 (1): 1-9.

Dalton, C., and J. Thatcher. 2014. "What Does a Critical Data Studies Look Like, and Why do we Care? Seven Points for a Critical Approach to 'Big Data'." Society and Space 29.

Edelman, M. 2014. "Food Sovereignty: Forgotten Genealogies and Future Regulatory Challenges." Journal of Peasant Studies 41 (6): 959-978.

Ettlinger, N. 2018. "Algorithmic Affordances for Productive Resistance." Big Data \& Society 5 (1): 2053951718771399.

Farhadi, B. 2018. "Narratives of Safety on Social Media: The Case of \#Mysafetyselfie." Professional Geographer 70 (1): 140-149. doi:10.1080/00330124.2017.1326083.

Fraser, A. 2018. "Land Grab / Data Grab: Precision Agriculture and its new Horizons." Journal of Peasant Studies. Advance online publication. doi:10.1080/03066150.2017.1415887.

Gingembre, M. 2015. "Resistance or Participation? Fighting Against Corporate Land Access Amid Political Uncertainty in Madagascar." Journal of Peasant Studies 42 (3-4): 561-584. doi:10.1080/03066150. 2015.1022867.

Goodman, M. K., J. Johnston, and K. Cairns. 2017. “Food, Media and Space: the Mediated Biopolitics of Eating." Geoforum; Journal of Physical, Human, and Regional Geosciences 84: 161-168. doi:10.1016/ j.geoforum.2017.06.017.

Gutierrez, M., and S. Milan. 2017. "Technopolitics in the Age of Big Data." In Networks, Movements \& Technopolitics in Latin America: Critical Analysis and Current Challenges, edited by F. S. Caballero and T. Gravante, 95-109. Basingstoke: Palgrave Macmillan. SSRN: https://ssrn.com/abstract= 2935141.

Hayles, N. K. 2017. Unthought: The Power of the Cognitive Nonconscious. Chicago: University of Chicago Press.

Herrod, E. 2016. "Ocado: Disrupting Itself with Technology." Internet Retailing, March 20, 2017. http:// internetretailing.net/issue/internetretailing-magazine-march-2017-issue-63-irm63/ocadodisrupting-technology/.

Iliadis, A., and F. Russo. 2016. "Critical Data Studies: An Introduction." Big Data \& Society 3 (2): 1-7. 
Joy, A., and J. F. Sherry Jr.. 2003. "Disentangling the Paradoxical Alliances Between art Market and art World." Consumption Markets \& Culture 6 (3): 155-181. doi:10.1080/1025386032000153759.

Juris, J. S. 2005. "The new Digital Media and Activist Networking Within Anti-Corporate Globalization Movements." The Annals of the American Academy of Political and Social Science 597 (1): 189-208.

Kit, T. C. 2016. "Big Data Feast Serves up Business Ideas for F\&B Players." Channel News Asia, September 14. http://www.channelnewsasia.com/news/business/big-data-feast-serves-upbusiness-ideas-for-f-amp-b-players-7829990.

Kitchin, R. 2014a. "Big Data, new Epistemologies and Paradigm Shifts." Big Data \& Society 1 (1): 2053951714528481. doi:10.1177/2053951714528481.

Kitchin, R. 2014b. The Data Revolution: Big Data, Open Data, Data Infrastructures and Their Consequences. London: Sage.

Kitchin, R. 2017. "Thinking Critically About and Researching Algorithms." Information, Communication \& Society 20 (1): 14-29.

Kloppenburg, J. 2014. "Re-purposing the Master's Tools: the Open Source Seed Initiative and the Struggle for Seed Sovereignty." Journal of Peasant Studies 41 (6): 225-1246.

Licoppe, C. 2004. "“'Connected" Presence: The Emergence of a New Repertoire for Managing Social Relationships in a Changing Communication Technoscape." Environment and Planning D: Society and Space 22 (1): 135-156.

Ling, R., and B. Yttri. 2002. "Hyper-coordination via Mobile Phones in Norway." In Perpetual Contact: Mobile Communication, Private Talk, Public Performance, edited by J. Katz and M. Aakhus, 139-169. Cambridge: Cambridge University Press.

Manjoo, F. 2017. "The Hidden Player Spurring a Wave of Cheap Consumer Devices: Amazon." New York Times, December 6. https://www.nytimes.com/2017/12/06/technology/cheapconsumer-devices-amazon.html.

McMichael, P. 2009. "A Food Regime Genealogy." Journal of Peasant Studies 36 (1): 139-169. doi:10. 1080/03066150902820354.

McMichael, P. 2012. "The Land Grab and Corporate Food Regime Restructuring." Journal of Peasant Studies 39 (3-4): 681-701. doi:10.1080/03066150.2012.661369.

McMichael, P. 2014. "Historicizing Food Sovereignty." Journal of Peasant Studies 41 (6): 933-957.

Milan, S. 2015. "From Social Movements to Cloud Protesting: the Evolution of Collective Identity." Information, Communication \& Society 18 (8): 887-900.

Milan, S. 2016. "Data Activism as the New Frontier of Media Activism." In Media Activism in the Digital Age, edited by V. Pickard and G. Yang, 151-163. Abingdon: Routledge.

Millar, G. 2016. "Knowledge and Control in the Contemporary Land Rush: Making Local Land Legible and Corporate Power Applicable in Rural Sierra Leone." Journal of Agrarian Change 16 (2): 206-224. doi:10.1111/joac.12102.

Moss, M. 2013. Salt, Sugar, fat: how the Food Giants Hooked us. London: WH Allen.

Neff, G., A. Tanweer, B. Fiore-Gartland, and L. Osburn. 2017. "Critique and Contribute: A PracticeBased Framework for Improving Critical Data Studies and Data Science." Big Data 5 (2): 85-97.

Nestlé. 2016. "Nestlé and Samsung to Collaborate on Digital Nutrition and Health." Nestlé, July 28, 2016. https://www.nestle.com/randd/news/allfeatures/nestle-samsung-collaboration-digitalnutrition-health.

Ocado. 2015. Ocado Annual Report, 2015. http://www.ocadogroup.com/ /media/Files/O/OcadoGroup/documents/fy15-annual-report-2015-v2.pdf.

Paasonen, S. 2016. "Fickle Focus: Distraction, Affect and the Production of Value in Social Media." First Monday 21 (10).

Pasquale, F. 2015. The Black Box Society. Cambridge: Harvard University Press.

Patel, R. 2007. Stuffed and Starved: Markets, Power and the Hidden Battle for the World Food System. London: Portobello.

Patel, R. 2009. "Food Sovereignty." Journal of Peasant Studies 36 (3): 663-706.

Pedersen, S., and S. Burnett. 2018. "'Citizen Curation" in Online Discussions of Donald Trump's Presidency: Sharing the News on Mumsnet." Digital Journalism 6 (5): 545-562.

Pickren, G. 2018. "The Global Assemblage of Digital Flow' Critical Data Studies and the Infrastructures of Computing." Progress in Human Geography 42 (2): 225-243. doi:10.1177/0309132516673241. 
Plume, K. 2016. "Monsanto's Climate Corp to Expand Digital Farming Platform." Reuters, August 17, 2016. http://www.reuters.com/article/us-monsanto-farming-data-idUSKCN10S1Q4.

PR Newswire. 2017. "PepsiCo Signs Strategic Agreement With Alibaba Group." PR Newswire, May 11. https://www.prnewswire.com/news-releases/pepsico-signs-strategic-agreement-with-alibabagroup-300455587.html.

Robbins, M. J. 2015. "Exploring the 'Localisation' Dimension of Food Sovereignty." Third World Quarterly 36 (3): 449-468.

Roberts, J. 2016. "Make Sense of the Data Overload." Marketing Week, October 20, 2016. https://www. marketingweek.com/2016/10/20/make-sense-of-the-data-overload/.

Rosenberg, S. 2007. Dreaming in Code: Two Dozen Programmers, Three Years, 4,732 Bugs, and one Quest for Transcendent Software. New York: Three Rivers Press.

Rosset, P. M., B. Machín Sosa, A. M. Roque Jaime, and D. R. Ávila Lozano. 2011. “The Campesino-toCampesino Agroecology Movement of ANAP in Cuba: Social Process Methodology in the Construction of Sustainable Peasant Agriculture and Food Sovereignty." Journal of Peasant Studies 38 (1): 161-191.

Schiavoni, C. M. 2017. "The Contested Terrain of Food Sovereignty Construction: Toward a Historical, Relational and Interactive Approach." Journal of Peasant Studies 44 (1): 1-32.

Schneider, T., K. Eli, A. McLennan, C. Dolan, J. Lezaun, and S. Ulijaszek. 2019. "Governance by Campaign: the co-Constitution of Food Issues, Publics and Expertise Through new Information and Communication Technologies." Information, Communication \& Society 22 (2): 172-192.

Srnicek, N. 2017. Platform Capitalism. Cambridge, UK/Malden, MA: Polity.

Thatcher, J., D. O'Sullivan, and D. Mahmoudi. 2016. "Data Colonialism Through Accumulation by Dispossession: New Metaphors for Daily Data." Environment and Planning D: Society and Space 34 (6): 990-1006.

The Nation (Thailand). 2016. "IoT, the Next Step in Local Digital Economy." The Nation (Thailand), July 25.

Tugby, L. 2017. "Analysis: How Ocado is Redefining Grocery Fulfilment." Retail Week, June 7, 2017. https://www.retail-week.com/sectors/grocery/analysis-how-ocado-is-redefining-groceryfulfilment/7021537.article?authent $=1$.

Twitter. 2017. "Venezuela libre de transgénicos" since:2013-01-01 until:2013-12-31. https://twitter. com/search?l=\&q=\%22venezuela\%20libre\%20de\%20transg\%C3\%A9nicos\%22\%20since\% 3A2013-01-01\%20until\%3A2013-12-31\&src=typd\&lang=en\&lang=en.

United Nations Development Programme. (2016). Human Development Report 2016: Human Development for Everyone. New York: United Nations.

Van der Velden, L. 2015. "Forensic Devices for Activism: Metadata Tracking and Public Proof." Big Data \& Society 2 (2): 2053951715612823.

Villi, M. 2012. "Social Curation in Audience Communities: UDC (User-Distributed Content) in the Networked Media Ecosystem." Participations: The International Journal of Audience and Reception Studies 9 (2): 614-632.

Wingfield, N., and M. J. de la Merced. 2017. "Amazon to Buy Whole Foods for \$13.4 Billion." New York Times, June 16. https://www.nytimes.com/2017/06/16/business/dealbook/amazon-whole-foods. html? $r=0$.

Wingfield, N., P. Mozur, and M. Corkery. 2018. "Retailers Race Against Amazon to Automate Stores." New York Times, April 1. https://www.nytimes.com/2018/04/01/technology/retailer-storesautomation-amazon.html.

Wittman, H. 2009. "Reworking the Metabolic Rift: La Vía Campesina, Agrarian Citizenship, and Food Sovereignty." Journal of Peasant Studies 36 (4): 805-826.

Wittman, H., A. A. Desmarais, and N. Wiebe. 2010. Food Sovereignty: Reconnecting Food, Nature and Community. Oxford: Pambazuka.

Zipkin, A. 2017. "Airports Are Losing Money as Ride-Hailing Services Grow." New York Times, December 11, 2017. https://www.nytimes.com/2017/12/11/business/airports-ride-hailingservices.html.

Zook, M. 2017. "Crowd-sourcing the Smart City: Using big Geosocial Media Metrics in Urban Governance." Big Data \& Society 4 (1): 2053951717694384. 